\title{
Ser Irmáo de uma Pessoa Surda: Relatos da Infância à Fase Adulta ${ }^{1}$ \\ BEING THE Sibling OF A DEAF PERSON: REPORTS FROM CHILDHOOD tO AdULTHOOD
}

\author{
Juliana Archiza YAMASHIRO² \\ Cristina Broglia Feitosa de LACERDA ${ }^{3}$
}

\begin{abstract}
RESUMO: o objetivo do presente estudo foi analisar a experiência de irmãos de pessoas surdas acerca de sua história de vida e das implicaçôes da deficiência nos relacionamentos fraternos. Tratou-se de um estudo exploratório, de abordagem qualitativa, que contou com a participaçáo de cinco irmáos de pessoas surdas com idade entre 31 a 44 anos. Para a coleta de dados foram utilizados os seguintes instrumentos: questionário de identificação e roteiro de entrevista em profundidade. Os dados obtidos foram analisados a partir do modelo de produçôes de sentido das práticas discursivas. Os principais resultados apontaram que a dificuldade de comunicação entre os participantes e seus irmáos surdos repercutiu em questóes nos relacionamentos desde a infância até a fase adulta. Considera-se que as questóes inerentes à deficiência trouxeram consequências a todos os membros da família, em especial nos quesitos relacionamentos e comunicação e que disponibilizar atenção especializada aos pais e irmãos destas pessoas auxiliaria no manejo das situaçôes vinculadas à deficiência e fortalecimento dos vínculos familiares.
\end{abstract}

PALAVRAS-CHAVE: Educação Especial. Irmãos. Pessoas com Deficiência. Família. Surdez.

\begin{abstract}
The aim of this study was to analyze the experience of deaf persons' siblings about their life stories and the implications of the disability in fraternal relationships. This was an exploratory study of qualitative approach, which included the participation of five siblings of deaf persons aged 31-44 years. The following instruments for data collection were used: identification questionnaire and in-depth interview guide. Data were analyzed from Social Representation Analysis. The main results showed that the difficulty in communicating with their deaf siblings reflected in difficulties in relationships that persisted from childhood to adulthood. It is considered that the issues relating to the disability brought repercussions to all family members, especially in the communication and relationship categories and that providing specialized care to the parents and siblings of deaf persons would help in coping with situations related to the disability and in strengthening family ties.
\end{abstract}

KEYWORDS: Special Education. Siblings. People with Disabilities. Family. Deafness.

\section{INTRODUÇÃo}

O relacionamento fraterno é constituído por uma complexidade de sentimentos e emoções ligados a elementos cognitivos, culturais e sociais, os quais desempenham papel fundamental na formação da identidade e personalidade dos sujeitos, ocupando assim um lugar singular no desenvolvimento. Ainda que tal relacionamento possa apresentar-se de modo competitivo, conflituoso e por vezes agressivo, em geral os irmáos são importantes fontes de apoio, companheirismo e cooperativismo, sendo essa ambiguidade, tão marcadamente presente nos relacionamentos com os irmãos, um importante e rico elemento de preparação para a vida social (GOLDSMID; FÉRES-CARNEIRO, 2011; TURNBULL; TURNBULL, 2001).

No que diz respeito aos relacionamentos estabelecidos em famílias de pessoas com deficiência, Oliveira et al. (2004) apontam que a família é palco da confluência de sentimentos

\footnotetext{
${ }^{1}$ http://dx.doi.org/10.1590/S1413-65382216000300005

${ }^{2}$ Doutoranda do Programa de Pós-Graduação em Educação Especial da Universidade Federal de São Carlos, UFSCar, São Carlos, SP, Brasil. julianayamashiro87@gmail.com

${ }^{3}$ Professora do Programa de Pós-Graduação em Educação Especial e do Curso de Licenciatura em Educação Especial da Universidade Federal de São Carlos, UFSCar, São Carlos, SP, Brasil. cristinalacerda@uol.com.br
} 
ambíguos e interinfluências positivas e negativas, e que tais dificuldades enfrentadas na convivência e nas relaçóes, são ainda intensificadas quando algo foge dos padróes de normalidade impostos pela sociedade.

Embora saiba-se sobre a importância da família para o desenvolvimento de seus integrantes, segundo Goldsmid e Féres-Carneiro (2011), estudos sobre os relacionamentos fraternos só ganham foco a partir do ano 2000. Quando se trata da identificação da realidade de famílias de pessoas com deficiência, o número de estudos com foco nos irmãos destas pessoas é ainda significativamente recente e evidencia a necessidade de aprofundamento sobre o tema (MATSUKURA; CID, 2004, 2008; NUNES; SILVA; AIELLO, 2008; MATSUKURA; YAMASHIRO, 2012; MESSA; FIAMENGHI JÚNIOR, 2010; NAVARAUSCKAS et al., 2010; PETEAN; SUGUIHURA, 2005; SOARES; FRANCO; CARVALHO, 2009; YAMASHIRO; MATSUKURA, 2013).

Quando esta realidade é tomada em análise em outra fase do desenvolvimento, como a adolescência ou a vida adulta, pode-se dizer que os estudos são ainda mais escassos (CAROLI; SAGONE, 2013; CHACON, 2010; GRAFF et al., 2012; TAYLOR et al., 2008; WOLFE et al., 2014).

Wolfe et al. (2014), por meio de um estudo comparativo entre irmãos adultos de pessoas com deficiência, de pessoas com doenças mentais e de pessoas com desenvolvimento típico, com o objetivo de analisar o curso de vida destes irmãos especialmente nos aspectos referentes à educação, ao trabalho e ao casamento, apontaram que irmãos de pessoas com doenças mentais têm menor nível educacional e menores chances de empregabilidade se comparado ao grupo de irmãos de pessoas com desenvolvimento típico. Enquanto os irmãos de pessoas com deficiência apresentaram maiores taxas de divórcio e menor número de casamentos.

Caroli e Sagone (2013), com o objetivo de explorar as atitudes de irmãos de pessoas com síndrome de Down, autismo ou deficiência intelectual em relação à deficiência, atentam para a necessidade de direcionar açóes de suporte para toda a família, ao evidenciar as difíceis repercussóes desta realidade no desenvolvimento dos irmáos. O estudo que contou com a participação de 140 adolescentes com desenvolvimento típico (13 a 18 anos), irmãos de pessoas com síndrome de Down, autismo e deficiência intelectual, revelou ainda que muitos destes irmãos acreditavam que as crianças com deficiência sempre seriam marginalizadas e que deveriam adquirir independência pessoal e autonomia.

O estudo realizado por Taylor et al. (2008), também relata sobre as difíceis situaçóes vivenciadas por irmãos de pessoas com deficiência. Os resultados apresentados por meio da participação de 268 irmáos adultos de pessoas com deficiência intelectual, 83 irmãos adultos de pessoas com doenças mentais e 791 irmãos de pessoas com desenvolvimento típico, revelaram que os irmãos adultos de pessoas com deficiência intelectual têm maior contato com os membros da família, mas pouca proximidade afetiva, enquanto os irmáos adultos de pessoas com doenças mentais reportaram maior estresse e menor bem estar psicológico se comparado aos irmãos de pessoas com desenvolvimento típico.

Com o objetivo de compreender a influência de uma pessoa com deficiência no desenvolvimento de seus irmáos não deficientes, o estudo realizado por Chacon (2010), o qual 
contou com a participação de 80 irmãos (14 a 26 anos) de pessoas com deficiência física, deficiência mental, deficiência auditiva e desenvolvimento típico, concluiu que as relaçóes fraternas estão parcialmente afetadas pela presença da deficiência a depender do tipo de deficiência, o que pode repercutir no funcionamento inter e intrapsíquico dos irmáos, como ansiedade, conflitos com os pais, menor sociabilidade, dentre outros.

Nessa direção, observa-se que os estudos sobre irmãos adolescentes ou adultos de pessoas com deficiência têm evidenciado questóes importantes presentes nas relaçóes fraternas e nas implicaçóes da deficiência para o desenvolvimento e curso de vida de todos os membros da família. Destacam ainda a necessidade de mais estudos que possam melhor compreender e aprofundar as características e os aspectos presentes nos relacionamentos familiares e no cotidiano de famílias de pessoas com deficiência.

Ao se tratar especificamente da surdez e não dos diversos tipos de deficiência de modo geral, estudos sobre famílias de pessoas surdas também têm buscado explorar as características peculiares presentes nos relacionamentos familiares e as implicaçóes da deficiência para todos os integrantes da família, uma vez que neste caso específico, a questão da comunicação apresenta-se como componente imprescindível no manejo da deficiência para cada um dos envolvidos.

Ao descrever alguns estudos sobre as interações e relações desenvolvidas pela criança surda e sua família, Brito e Dessen (1999) apontam que há também neste campo uma escassez de pesquisas que abordem tais interaçóes. A partir desta revisão observa-se ainda que os poucos estudos encontrados objetivam compreender as relações entre a mãe ou o pai e a criança surda e as implicaçóes destas relaçóes para o desenvolvimento da criança, evidenciando assim, que os outros filhos não têm sido foco dos estudos desenvolvidos na área.

Discorrendo acerca do papel da família junto ao filho surdo, Negrelli e Marcon (2006) atentam para a importância da linguagem e da comunicação no desenvolvimento psicológico e social dos membros da família. A partir da revisão de literatura realizada pelos autores, evidencia-se que a dificuldade de comunicação constitui o principal empecilho no relacionamento do filho surdo com os demais membros da família, podendo resultar em problemas emocionais, distanciamento e dificuldades no estabelecimento de vínculos afetivos, dentre outros.

Isso ocorre quando a criança surda é filha de pais ouvintes (maior parte dos casos). Segundo Oliveira et al. (2004), a relação do surdo com a família está marcada pela perspectiva da diferença, uma vez que a língua de interação entre os membros da família é a língua oral e esta não é acessível à pessoa surda. A língua de acesso a ela é a de sinais e, em geral, a família e seus membros não são usuários da mesma e teriam que aprendê-la para se comunicar com o membro surdo. Assim, a falta de conhecimento na língua de sinais é um dos principais efeitos causadores de dificuldades no relacionamento entre crianças surdas e seus familiares.

Destaca-se que a criança surda tem o potencial para a aprendizagem da língua de sinais, mas só poderá adquiri-la se tiver contatos interacionais com usuários efetivos da mesma. Neste sentido, a sua língua materna (a língua da mãe e familiares) não favorece a sua constituição como sujeito. Ela depende de uma língua estrangeira à família (a língua de sinais) e de oportunidades de contato com a mesma para seu desenvolvimento. A família então tem papel 
determinante em oferecer estas oportunidades e em constituir-se ela mesma em usuária desta língua ou não (MOURA, 2013).

A aquisição da língua de sinais ou a comunicação efetiva entre familiares e crianças surdas repercute diretamente na qualidade da convivência e interação de todos os membros da família, no entanto, em geral a mãe é aquela que melhor se comunica com a criança surda (OLIVEIRA et al., 2004).

Dada a importância da comunicação para os relacionamentos familiares e consequentemente para o desenvolvimento dos membros da família, faz-se imprescindível ampliar a compreensáo acerca de como a comunicação e o convívio com uma criança surda implicou nas histórias de vida de seus irmãos e nos relacionamentos estabelecidos entre eles.

Destaca-se ainda a escassez de estudos acerca da realidade vivenciada por irmãos de pessoas surdas, evidenciando a necessidade de aprofundamento no tema para que seja possível compor um panorama maior sobre as experiências destes irmãos, bem como sobre implicaçóes de tal realidade para o desenvolvimento dos laços fraternos, necessidades de apoio e relacionamentos familiares. Nesta direção o presente estudo objetivou analisar a experiência de irmãos de pessoas surdas acerca de sua história de vida e das implicaçóes da deficiência nos relacionamentos fraternos.

\section{MÉTOdo}

Trata-se de um estudo descritivo, exploratório de abordagem qualitativa.

\subsection{AspeCtos éticos}

O presente projeto foi submetido ao Comitê de Ética em Pesquisa com Seres Humanos da Universidade Federal de São Carlos - UFSCar (Parecer número 841.091). Após aprovação, os participantes receberam um termo de consentimento livre e esclarecido através do qual foram explícitos os objetivos da pesquisa. Após a assinatura do termo a coleta de dados foi iniciada.

\subsection{Participantes}

Foram participantes do estudo cinco irmãos de pessoas surdas residentes de uma cidade de médio porte do interior do estado de São Paulo.Como critérios de inclusão os participantes deveriam ter idade igual ou superior a 18 anos e; ter morado na mesma residência que seu irmão surdo durante os períodos da infância e da adolescência.

A composição da amostra foi realizada de modo intencional, utilizando-se a técnica snowball (VICTORIA; KNAUTH; HASSUN, 2000). Tal técnica prevê que por meio da localização de um (ou de alguns) participante (s) os seguintes sejam localizados a partir da indicação dos primeiros. 


\subsection{InSTRumentos De Medida}

1. Questionário de Identificação: com o objetivo de obter dados pessoais dos participantes do estudo;

2. Roteiro de Entrevista em Profundidade: com questóes que abordaram aspectos relativos à infância, à adolescência e à fase de vida atual dos participantes; à convivência dos mesmos com o irmão surdo; sua comunicação; relacionamentos, dentre outros.

\subsection{Forma de Análise dos Resultados}

Como forma de análise dos dados foi utilizado o modelo de produção de sentidos das práticas discursivas proposto por Spink, que se trata de uma metodologia de análise das representações sociais (SPINK, 2000).

Com embasamento teórico pautado no construcionismo e na psicologia social, os quais emergem da perspectiva de que a obtenção do conhecimento deve se constituir com base nos processos de interação humana importando o conhecimento que as pessoas têm de suas realidades, muito mais do que a compreensão intelectualista restrita ao conhecimento teórico, as práticas discursivas situam-se e constituem-se o foco central de análise na abordagem construcionista (SPINK, 2000). Sob esta perspectiva, "ao relacionar práticas discursivas com produção de sentidos, estamos assumindo que os sentidos não estão na linguagem como materialidade, mas no discurso que faz da linguagem a ferramenta para a construção da realidade" (SPINK, 2000, p.193).

Para fazer aflorar os sentidos, a partir dos discursos coletados, desenvolvem-se os mapas de associação de ideias, os quais têm por objetivo "sistematizar o processo de análise das práticas discursivas em busca de aspectos formais da construção linguística, dos repertórios utilizados nessa construção e da dialogia implícita na produção de sentidos” (SPINK, 2000, p.107). Dessa forma, os mapas constituem-se como instrumentos de visualização que subsidiam e auxiliam nos demais processos de interpretação.

Para a construção dos mesmos é feita uma definição das categorias gerais de natureza temática, as quais organizam os conteúdos, procurando preservar a sequência das falas e identificar os processos de interação dialógica a partir dos esquemas visuais da entrevista como um todo. Neste sentido, o diálogo é mantido em sua integralidade e originalidade sendo deslocado para as categorias definidas em função dos objetivos da pesquisa (SPINK, 2000).

Para tanto, as entrevistas foram gravadas em áudio e transcritas em sua íntegra.

\section{Resultados e discussáo}

Apresenta-se a seguir, nos Quadros 1 e 2 a caracterização dos participantes da pesquisa e de seus irmãos surdos. 


\begin{tabular}{|l|l|c|l|l|l|l|l|l|l|}
\hline & Sexo & Idade & Profissáo & Escolaridade & $\begin{array}{l}\text { Estado } \\
\text { Civil }\end{array}$ & Religiáo & Filhos & $\begin{array}{l}\text { Com } \\
\text { quem } \\
\text { reside }\end{array}$ & $\begin{array}{l}\text { Outros } \\
\text { irmáos }\end{array}$ \\
\hline $\mathbf{1}$ & Masculino & 44 & Pedreiro & $\begin{array}{l}\text { Ensino } \\
\text { Médio }\end{array}$ & Solteiro & Católica & - & $\begin{array}{l}\text { Pais e } \\
\text { irmáo }\end{array}$ & $\begin{array}{l}\text { Mais 3 } \\
\text { irmáos }\end{array}$ \\
\hline $\mathbf{2}$ & Feminino & 32 & $\begin{array}{l}\text { Administrador } \\
\text { de Empresas }\end{array}$ & $\begin{array}{l}\text { Ensino Supe- } \\
\text { rior }\end{array}$ & Casada & Católica & 1 & $\begin{array}{l}\text { Esposa e } \\
\text { filha }\end{array}$ & - \\
\hline $\mathbf{3}$ & Feminino & 34 & Pedagoga & $\begin{array}{l}\text { Ensino Supe- } \\
\text { rior }\end{array}$ & Casado & Católica & 4 & $\begin{array}{l}\text { Esposo e } \\
\text { filhos }\end{array}$ & $\begin{array}{l}\text { Mais 3 } \\
\text { irmáos }\end{array}$ \\
\hline $\mathbf{4}$ & Feminino & 31 & $\begin{array}{l}\text { Auxiliar de } \\
\text { Escritório }\end{array}$ & $\begin{array}{l}\text { Ensino } \\
\text { Médio }\end{array}$ & Casado & Católica & 1 & $\begin{array}{l}\text { Esposo e } \\
\text { filho }\end{array}$ & - \\
\hline $\mathbf{5}$ & Masculino & 33 & Motoboy & $\begin{array}{l}\text { Ensino } \\
\text { Médio }\end{array}$ & Casado & Católica & 2 & $\begin{array}{l}\text { Esposa e } \\
\text { filhas }\end{array}$ & $\begin{array}{l}\text { Mais 2 } \\
\text { irmãos }\end{array}$ \\
\hline
\end{tabular}

Quadro 1 - Caracterizaçáo dos participantes.

Fonte: elaboração própria.

Observa-se que dois participantes eram do sexo masculino enquanto três eram do sexo feminino. A idade de quatro participantes variou de 31 a 34 anos e apenas um possuía mais de 40 anos. Três concluíram o ensino médio e dois deles o ensino superior. Quatro declararam ser casados, todos autodenominaram-se católicos e além do irmão surdo, três participantes declaram possuir ainda mais dois e três irmãos.

\begin{tabular}{|l|c|l|l|l|l|l|l|l|}
\hline $\begin{array}{c}\text { Irmáo } \\
\text { (Sexo) }\end{array}$ & Idade & Profissáo & $\begin{array}{l}\text { Escolari- } \\
\text { dade }\end{array}$ & $\begin{array}{c}\text { Estado } \\
\text { Civil }\end{array}$ & Religiáo & $\begin{array}{c}\text { Com } \\
\text { quem } \\
\text { reside }\end{array}$ & $\begin{array}{l}\text { Sobre a } \\
\text { surdez }\end{array}$ & $\begin{array}{c}\text { Como se } \\
\text { comunica }\end{array}$ \\
\hline Masculino & 40 & $\begin{array}{l}\text { Professor de } \\
\text { Libras }\end{array}$ & $\begin{array}{l}\text { Superior } \\
\text { Incompleto }\end{array}$ & Solteiro & Católica & $\begin{array}{l}\text { Pais e } \\
\text { irmão }\end{array}$ & $\begin{array}{l}\text { Adquiriu } \\
\text { aos 5 anos }\end{array}$ & $\begin{array}{l}\text { Libras, leitura } \\
\text { labial e fala }\end{array}$ \\
\hline Masculino & 35 & Metalúrgico & $\begin{array}{l}\text { Ensino } \\
\text { Médio }\end{array}$ & Casado & Evangélico & $\begin{array}{l}\text { Esposa e 2 } \\
\text { filhos }\end{array}$ & Nascença & $\begin{array}{l}\text { Libras, leitura } \\
\text { labial e fala }\end{array}$ \\
\hline Feminino & 31 & $\begin{array}{l}\text { Adminis- } \\
\text { trador de } \\
\text { Empresas }\end{array}$ & $\begin{array}{l}\text { Ensino } \\
\text { Superior }\end{array}$ & Casada & Católica & $\begin{array}{l}\text { Marido e } \\
\text { 2 filhas }\end{array}$ & Nascença & $\begin{array}{l}\text { Libras, leitura } \\
\text { labial e fala }\end{array}$ \\
\hline Feminino & 33 & $\begin{array}{l}\text { Auxiliar de } \\
\text { Escritório }\end{array}$ & $\begin{array}{l}\text { Ensino } \\
\text { Médio }\end{array}$ & Casada & Católica & $\begin{array}{l}\text { Pai, } \\
\text { marido e 1 } \\
\text { filha }\end{array}$ & $\begin{array}{l}\text { Adquiriu } \\
\text { com 1 ano } \\
\text { e 8 meses }\end{array}$ & $\begin{array}{l}\text { Libras, leitura } \\
\text { labial e fala }\end{array}$ \\
\hline Feminino & 29 & $\begin{array}{l}\text { Auxiliar de } \\
\text { Escritório }\end{array}$ & $\begin{array}{l}\text { Ensino } \\
\text { Superior }\end{array}$ & Solteira & Católica & Pais & Nascença & $\begin{array}{l}\text { Libras, leitura } \\
\text { labial e fala }\end{array}$ \\
\hline
\end{tabular}

Quadro 2 - Caracterização dos irmãos surdos.

Fonte: elaboração própria.

Sobre seu irmão surdo, os participantes informaram que dois eram homens e três mulheres, com idade variada de 29 a 40 anos. Todos possuíam vínculo empregatício, dois deles náo eram casados, quatro pertenciam a religião católica e um, evangélica. Três nasceram com surdez enquanto dois adquiriram-na com um ano e cinco anos de idade. Além disso, todos se comunicavam por meio da língua de sinais, de leitura labial e oralização. 
Vale ressaltar ainda que, segundo o relato dos participantes, nenhum membro da família tem domínio e faz uso da língua de sinais para se comunicar com o familiar surdo, sendo que este faz uso dessa língua somente entre seus amigos surdos e na comunidade surda da cidade.

Referindo-se às dificuldades enfrentadas por irmãos de pessoas com deficiência, Taylor et al. relatam que tais irmãos tendem até mesmo a alterar o curso de suas vidas diante da tomada de decisóes importantes devido ao senso de responsabilidade que possuem perante o irmão deficiente (TAYLOR et al., 2008).

Ainda que não estejam especificamente falando acerca da responsabilização que sentem pelo irmão surdo, as falas a seguir evidenciam algumas das preocupaçóes que os participantes tinham com o irmão surdo desde o período da infância, as quais perduram até os dias atuais.

Preocupação? [...] aquela coisa de saber o que ela estava querendo dizer e de brincar e da gente tá junto. (Participante 3)

Sim. Me preocupava muito. De não casar, de acontecer alguma coisa com a minha mäe e ela ficar [...] era a preocupação da minha mãe também, dela não casar, de não ter filho. (Participante 4)

As vezes eu ficava meio preocupado, ele sempre foi muito doente. Eu via as correrias que meu pai e minha mãe as vezes saiam, faziam com ele né?! (...) Ainda hoje, porque ele sempre quis arrumar um emprego bom e nunca conseguia, tem esse preconceito das empresas né? Até hoje ainda: bate, bate, bate. Arruma um emprego em firma, mas nessas empresas que pra cumprir vaga de deficiente, então eles tem que... e fica lá, não dá chance de promoção, fica lá. (Participante 1)

Observa-se a partir dos excertos expostos que os participantes adultos possuíam preocupações com seus irmãos surdos desde a infância, relativas à comunicação e à inclusão nas atividades infantis, como exemplo. Além disso, observa-se ainda que tais sentimentos se modificaram ao longo do curso de vida, mas não se findaram, conforme evidenciado acerca das preocupaçóes atuais relativas à vida sentimental e profissional do irmáo surdo.

Sobre este tema, Atkin et al. (2002) relatam que pais de pessoas surdas têm preocupações sobre as habilidades de negociar satisfatoriamente transiçóes daquilo que se denomina como "normal" para pessoas ouvintes como, aquisição de uma boa formação, habilidades sociais e, o desempenho de papéis da vida adulta, como casar-se e ter um emprego. Nesse sentido os autores focalizam a crença de tais pais de que a presença da surdez apresenta barreiras adicionais aos filhos, as quais dificultam o desenvolvimento e desempenho dos papéis da vida adulta.

Dessa forma, os resultados provenientes com as respostas dos participantes do presente estudo parecem sugerir que as preocupações vivenciadas por pais de pessoas surdas também são compartilhadas pelos irmãos destas pessoas, os quais vivenciam intimamente as dificuldades enfrentadas pelo familiar surdo e seus pais.

Além das preocupaçóes que irmãos de pessoas surdas parecem compartilhar com seus pais, os resultados do presente estudo também sugerem outros sentimentos e reaçóes vivenciadas por ambas as geraçóes, como aqueles relativos ao enfrentamento da notícia e manejo da situação.

É a gente sempre esperou quando fosse possivel um tratamento, mas quando ele era criança ainda, eu me lembro muito bem, devia ter uns doze anos, meu pai levou ele pra outra cidade, pra fazer uns exames. Foi aí que os médicos constataram que o problema dele era só com aparelho, não tinha cirurgia, não tinha tratamento. Naquela época eu senti muito, chorei bastante. A gente esperava... quando meu pai 
vinha trazer ele, a gente esperava assim que fosse um tratamento que ele ficasse bom, quando veio a notícia, meu pai falou "o problema dele não tem solução". Chorei bastante. (Participante 1)

Ter uma criança surda traz consequências psicológicas e sociais aos pais ouvintes. Isso inclui sentimentos de culpa, frustração, ansiedade, ressentimento, dentre outros. Muitos pais vêem o nascimento de uma criança surda como algo trágico (ATKIN et al., 2002; BITTENCOURT; MONTAGNOLI, 2007). Contudo, a partir do exposto pelo excerto acima, tais sentimentos adversos parecem não ser vivenciados apenas pelos pais da criança, mas influenciam e afetam também os seus irmãos, que vivenciam e presenciam tais experiências.

Sobre o assunto, Yamashiro e Matsukura (2013) realçam a importância de que irmãos de crianças com deficiência sejam informadas acerca da deficiência da criança a partir de suas dúvidas e capacidade de compreensão. Nesse sentido, a atuação profissional junto aos demais membros da família mais uma vez mostra-se como imprescindível para o apoio durante o enfrentamento, manejo e vivência da situação.

Outra questão importante presente nos discursos dos participantes referiu-se à comunicação e ao relacionamento estabelecido entre eles e seus irmãos surdos. Tal tema ficou evidente diante da dificuldade enfrentada por estas e outras famílias que possuem em sua composição um membro com surdez de comunicar-se e relacionar-se. Diante destas dificuldades, observa-se a seguir, a partir do relato dos irmãos participantes, que suas famílias desenvolviam maneiras específicas para lidar com a situação.

A gente procurava falar sempre de frente pra ela. Então de comunicação a gente teve assim problema básico, as vezes a gente esquecia que ela era surda... Então de falar nas costas... lembra! Cutuca! Fala olhando pra ela... coisas assim. (Participante 3)

A gente conversa normal, só que ninguém sabe Libras ${ }^{4}$ né? Então tem que conversar assim de maneira que ele entende. Então as vezes ele pergunta assim, as vezes a gente fala alguma coisa, pára e explica pra ele. As vezes, ele nem senta perto da gente, falo "não, tem uma cadeira aqui, você vai sentar junto com a gente". (Participante 1)

A gente conversava entre nós, conversávamos normal. Ai ele perguntava o que nós estávamos falando. Ai tinha que passar pra ele, entendeu? E até hoje é assim. Que nem, se tivéssemos aqui, eu não ia conversar com você fazendo mímica pra ele entender o que nós estávamos fazendo. Então eu ia conversar com você e "o que vocês falaram?"... "eu falei que quando você era criança, conversava..." tinha, tem que ficar explicando. (Participante 2)

Os estudos da área têm apontado para estas dificuldades presentes no cotidiano de famílias com pessoas surdas e nas diferentes formas de manejo da situação de acordo com o acesso às informações, as características de cada família e também em função das concepçóes que fazem acerca da surdez (ATKIN et al., 2002; BITTENCOURT; MONTAGNOLI, 2007; HADJIKAKOU; NIKOLARAIZI, 2008; NEGRELLI; MARCON, 2006; REZENDE; KROM; YAMADA, 2003).

Nos três excertos apresentados, evidenciam-se as diferentes formas com que as famílias se organizam para comunicar-se na presença do familiar surdo. Os dois primeiros demonstram a preocupação de todos os envolvidos para não excluírem a pessoa surda dos assuntos comentados, contudo, o último evidencia um outro tipo de atitude, na qual o familiar surdo só

${ }^{4}$ Libras (Língua Brasileira de Sinais) 
tem acesso aquilo que for de seu interesse, uma vez que a família não se dirige especificamente para ele, mas esclarece suas dúvidas quando estas são emitidas.

Este último resultado não difere dos apontamentos da literatura da área referente a este tema. Hadjikakou e Nikolaraizi (2008) relatam que muitas vezes os membros da família direcionam atenção ao familiar surdo, conferindo assim acesso à conversação e à informação, somente quando percebem uma necessidade específica dele, o que faz com que tal pessoa nem sempre tenha acesso e efetiva participação nas conversaçóes familiares. Além disso, segundo os 24 adultos surdos participantes do estudo citado, alcançar uma comunicação, similar ao que é feito por meio do uso da língua de sinais, oralmente com seus familiares ouvintes, não se trata de algo plenamente possível, uma vez que consideram esta forma de comunicação como limitada (HADJIKAKOU; NIKOLARAIZI, 2008). Desse modo, o presente estudo sugere que, ainda nos casos das famílias que se atentam por incluir o indivíduo surdo em suas conversaçóes orais, as diferenças presentes nas duas modalidades de comunicação, isto é, na língua oral e na língua de sinais, representa por si só um importante empecilho a ser enfrentado em busca de uma comunicação profunda e significativa entre familiares ouvintes e surdos.

Entretanto, não somente diante da participação dos assuntos familiares, as dificuldades impostas pelas diferentes maneiras de comunicação imprimem ainda importantes questóes no estabelecimento de vínculos e relacionamentos entre os membros da família e a pessoa surda.

Ele ficava muito pouco com a gente e quando ficava a gente brigava pra caramba. Era sempre muita briga. Principalmente ele e eu. Era complicado. E brigas violentas mesmo, sangrentas. Eu lembro de brincadeiras assim em viagens, momentos felizes que eu tive com ele, mas no dia a dia era sempre muita briga. Era terrível mesmo. Então assim, o relacionamento com ele... é zero. Não tinha. E não tem até hoje. (Participante 2)

Porque a relação com ela era meio tumultuada por conta da gente se entender no toque... entáo ela sempre foi muito mais forte que eu, então ela ia chamar e quando ela tocava acabava empurrando... e a gente não batia nela, nada, mas... (Participante 3)

A gente não tinha muito relacionamento, ela era a mais nova, então a amizade dela era outra, a amizade minha era outra. E o fato até dela ser surda incomodava um pouco também, tanto ela como eu também... não tinha conhecimento também do que é, então era meio conturbado... a gente não tinha muito relacionamento na adolescência, na infância, foi ter mais agora mesmo. (Participante 5)

Observa-se a partir dos relatos apresentados que adicionalmente às dificuldades comuns enfrentadas entre irmãos com desenvolvimento típico para a formação dos vínculos fraternos, como a diferença de idade ou a diferença entre os sexos, nos casos específicos de um dos envolvidos ser surdo soma-se a dificuldade de encontrar e estabelecer um meio de comunicação favorável à formação e manutenção dos vínculos. Nestes casos, observa-se ainda que as dificuldades impostas pela limitada comunicação repercutiram significativamente durante os períodos da infância e da adolescência no estabelecimento de tais vínculos.

Sobre esse assunto, outros discursos proferidos pelos participantes do presente estudo revelam o desejo de que isso pudesse ser diferente, diante do grande impacto que a falta de comunicação imprimia na qualidade dos relacionamentos, como se observa a seguir.

Eu desejava, eu queria... eu sempre quis ter uma outra irmã, mais uma irmá. Porque eu queria ter uma irmá em casa, porque o surdo ele é... eu gostaria de ter uma outra irmá pra conversar... aquela 
coisa de, a noite você desligou a luz, acabou, você não conversa mais. E ela é muito geniosa, então se ela não tava afim ela fechava o olho, então não tinha nem como terminar uma discussão. (Participante 3) A nossa comunicação sempre foi muito ruim, então, tem uma coisa que eu gostaria de mudar na minha infância? Tem, que ele não fosse surdo. Só isso. (Participante 2)

A partir do exposto, os achados do presente estudo corroboram ao apresentado pela literatura da área acerca da evidente necessidade de direcionar atenção a estes familiares de modo a auxiliar no manejo da situação frente às dificuldades advindas da falta de comunicação e estímulo da formação de laços profundos e saudáveis (HADJIKAKOU; NIKOLARAIZI, 2008).

Sendo a linguagem um símbolo da cultura, etnia e um veículo central para a construção compartilhada de identidades e definição de grupos, encontrar um modo de comunicação mútuo entre os membros da família e a criança surda, independente da modalidade de comunicação, auxilia na garantia de uma comunicação efetiva e trocas reais de experiências (ATKIN et al., 2002; HADJIKAKOU; NIKOLARAIZI, 2008).

Nessa mesma direção, uma outra narrativa evidencia a necessidade de apoio e acesso à informação vivenciada por familiares membros de uma pessoa surda, como se observa a seguir.

Hoje eu penso assim que o fato de náo conseguir conversar foi assim, foi muito ruim. Muito ruim, muito ruim pra todo mundo. Se desde o início tivesse um apoio familiar, "você tem que aprender a se comunicar em Libras" hoje eu vejo que é essencial, porque você não conseguir expressar o que você está pensando é terrivel, isso dava um estresse muito grande na gente e ele ficava nervoso pra se expressar porque a gente estava nervoso... e dava briga. Era realmente terrivel e é até hoje. (Participante 2)

A necessidade de apoio informada pelo participante demonstra ainda o quanto tais familiares têm reduzido suporte e o quanto os profissionais envolvidos com os cuidados de crianças com deficiência deveriam direcionar atenção e envolver os demais membros da família de modo a esclarecer suas dúvidas e proporcionar informaçóes.

Além de discorrer acerca de seu próprio relacionamento com o irmão surdo, um dos participantes também apontou para questóes evidentes presentes nos relacionamentos entre o pai e o irmão surdo.

\begin{abstract}
A falta de comunicação afetou em tudo até hoje, então eu acho que meu pai... meu pai faleceu porque ele estava infeliz, e eu acho que assim, uma boa parcela dessa infelicidade foi o fato dele não ter um bom relacionamento com of filho dele (...) ele era infeliz porque ele tinha essa dificuldade com o meu irmão. Ele expressava, não sou eu que estou falando, ele expressava que ele era infeliz com isso. (Participante 2)
\end{abstract}

Tal resultado corrobora ao apontado na literatura da área acerca dos relacionamentos entre os pais e seus filhos surdos. Atkin et al. (2002) relatam que fortes relacionamentos estabelecidos entre os pais e seus filhos surdos são incomuns sendo que a dificuldade de comunicação se revela como uma das principais razóes para a dificuldade de estreitamento de laços. No entanto, tal estudo, que contou com a participação de 70 jovens surdos e 15 membros de suas famílias, revelaram que embora em número relativamente pequeno, existem famílias de pessoas surdas que não referem problemas de comunicação e evidenciam que o pai e o filho surdo podem fortalecer relacionamentos por meio de um investimento na comunicaçáo. Ainda 
segundo os autores, limitaçôes na comunicação fazem com que frequentemente a pessoa surda sinta-se excluída, o que implica ainda na dificuldade da formação de laços fortes entre ela e seus familiares, com destaque para dificuldades em comunicar-se sobre assuntos profundos e íntimos (ATKIN et al., 2002).

Sobre o assunto, Oliveira et al. (2004) apontam que a mãe em geral é quem melhor se comunica com o filho surdo. Nessa direção, destaca-se a importância de que os profissionais envolvidos com o cuidado da pessoa surda estejam também atentos para as necessidades de outros membros de sua família, especificamente dos pais e dos irmãos, de modo a favorecer o acesso a informaçóes relativas à deficiência e acolhimento não somente às mães, pois acredita-se que tal estímulo possa favorecer o estabelecimento de uma melhor comunicação e fortalecimento de laços (ATKIN et al., 2002; BITTENCOURT; MONTAGNOLI, 2007; BITTENCOURT; HOEHNE, 2009).

Outra importante questão trazida pelos participantes do estudo diz respeito a educação com que foram criados pelos pais e a influência da surdez nas diferentes formas de educar, como se observa a seguir.

Porque assim, meu pai teve sempre muita resistência também pra querer aprender as coisas. E a gente também... nós acabamos näo indo atrás de aprender, de aprimorar essa linguagem, então nós transferiamos pra ele toda a responsabilidade dele ter que entender a gente e de que ele pudesse se expressar bem para que nós pudéssemos entender e tal. Só que nisso muitas coisas foram deixando pra trás, na própria questão da educação. Meus pais não souberam lidar com a deficiência. Que nem, sempre foi muito comparado a questão da minha educação e da educação dele, porque? Quando eu fazia alguma coisa de errado, meus pais conseguiam chegar e falar: "Olha você não pode fazer isso, por esse motivo", já com ele, como não tinha esse mecanismo de comunicação, "você não pode fazer isso", "porque?" "porque não pode". Era difícil explicar as coisas. (Participante 2)

A gente nunca teve assim muita diferença. E quando a professora começou a atender minha irmä, ela falou "olha, vocês têm dois filhos, ela é mais uma filha, ela exige alguns cuidados, mas ela é mais uma filha, então vocês eduquem igual porque senão ela vai virar bicho", foi bem essas as palavras. Então tudo o que os meus pais faziam pra gente, era igual pra ela, então dentro de casa não tinha essa comparação, então nós fomos crescendo juntos. Meu pai sempre usou barba, aí a professora falou pra ele "olha, corta pra ficar o recorte da boca, ela precisa ver sua boca". Outro exemplo, nosso comércio não abre de domingo, um pouco por conta dela. Porque no domingo a gente reza em família. Domingo é o dia do Senhor e tal. Como que é o dia do Senhor se é o dia de trabalhar? Como que é o dia de guardar, se vai trabalhar? Então é o concreto. E ai o meu pai começou a se questionar com relaçâo a isso, porque ele falou "como que ela vai entender isso?", pros outros eu falo, faço, contorno a situação, mas como é que ela vai entender? Então ele parou de trabalhar no domingo, pra ser uma coisa verdadeira. Por conta dessa educação, não se abre espaço pra outras coisas. Porque meus pais tiveram que ser coerentes. A deficiência auditiva dela que forçava, ou lembrava dessa coerência, o tempo todo. Então a nossa educação foi muito tranquila. (Participante 3)

A partir dos excertos apresentados observa-se que a questão da surdez, também impactou na forma com que as famílias reagiram frente a tomada de decisão na criação de todos os filhos. O primeiro relato revela que o manejo dos pais frente a deficiência não foi capaz de contemplar a criação dos filhos de modo igualitário frente às suas diferenças, enquanto na segunda declaração a preocupação dos pais somada ao acesso à informação sobre a deficiência e apoio profissional, parecem ter resultado no oferecimento de uma educação aos filhos mais coerente e igualitária, de acordo com a visão dos filhos participantes. Assim, as diferente formas de lidar 
com a deficiência e as implicaçóes destas formas no trato dos filhos revelou ainda que mais uma vez as informaçóes recebidas pelos profissionais atuantes com esta população aparecem como ferramentas imprescindíveis para uma tomada de decisões mais positiva.

Além disso, compreender a visão do contexto da deficiência na família, clarificando os mitos familiares presentes na relação da família com a deficiência auditiva e as repercussões de tais mitos e significados para o desenvolvimento dos membros da família e seus relacionamentos auxiliaria na identificação de novos caminhos para lidar com a deficiência e compreender o significado da mesma para família e o sujeito (REZENDE; KROM; YAMADA, 2003).

Tais autores indicam ainda que há uma construção de mitos ao redor da vivência da realidade de se ter um membro da família com surdez que nem sempre têm como fonte primária de causa e significado a deficiência em si, mas as condições histórico-culturais vivenciadas pelas famílias (REZENDE; KROM; YAMADA, 2003).

Desta forma, direcionar atenção especializada e disponibilizar informaçôes a todos os envolvidos com a pessoa surda parece ser imprescindível para que as dificuldades impostas pelas diferenças sejam reduzidas e para que o entendimento, enfrentamento e vivência de tal realidade sejam realizados com suporte e de maneira a otimizar e facilitar o desenvolvimento dos vínculos e laços familiares, questóes que vão para além do cuidado da criança surda em si, mas que refletem diretamente na qualidade de vida de todos os envolvidos.

\section{Consideraçóes finais}

Diante dos relatos proferidos pelos participantes do presente estudo, observa-se que a realidade de ter um irmáo com surdez repercutiu em implicaçóes no desenvolvimento e fortalecimento dos laços fraternos náo somente no período da infância e da adolescência, mas também da vida adulta, sendo que a comunicação apresentou-se como principal componente causador das dificuldades enfrentadas nos relacionamentos e vivências compartilhadas.

Além disso, importa notar que o fato das famílias participantes não terem acessado a língua de sinais utilizada por seus filhos surdos logo no período da infância da criança, implicou no estabelecimento de vínculos familiares permeados por fragilidades e dificuldades, além de questóes evidentes na própria educação administrada aos filhos, dificuldades e questóes que perpetuaram até a fase de vida adulta.

Dessa forma, o presente estudo apontou para a importância de envolver os demais membros da família, não somente as mães, como também os pais e os irmãos, nas orientações recebidas pelos profissionais atuantes com esta população. Acredita-se assim que propiciar o acolhimento, a escuta e o esclarecimento de dúvidas com informaçóes sobre a deficiência e maneiras de lidar com a situação, representam ferramentas que poderiam auxiliar na quebra das dificuldades impostas pelas diferentes formas de comunicação e, no desenvolvimento de laços familiares mais profundos e saudáveis.

Assim, o presente estudo respondeu aos objetivos propostos pela pesquisa uma vez que foi possível aprofundar o conhecimento que se tem acerca da história de vida de irmãos adultos de pessoas surdas e as implicaçóes desta realidade para os relacionamentos fraternos da infância à vida adulta. 


\section{REFERÊNCIAS}

ATKIN, K. et al. Young South Asian deaf people and their families: negotiating relationships and identities. Sociology of Health \& Illness, Malden, v.24, n.1, p.21-45, 2002.

BITTENCOURT, Z.Z.L.C.; HOEHNE, E.L. Qualidade de vida de familiares de pessoas surdas atendidas em um centro de reabilitação. Ciênc. Saúde Coletiva, Rio de Janeiro, v.14, n.4, p.1235-1239, 2009.

BITTENCOURT, Z.Z.L.C.; MONTAGNOLI, A.P. Representaçóes sociais da surdez. Medicina, Ribeirão Preto, v.20, n.2, p.243-249, 2007.

BRITO, A.M.W.; DESSEN, M.A. Crianças surdas e suas famílias: um panorama geral. Psicol. Reflex. Crit., Porto Alegre, v.12, n.2, p.429-445, 1999.

CAROLI, M.A.; SAGONE, E. Siblings and disability: a study on social attitudes toward disabled brothers and sisters. Procedia - Social and Behavioral Sciences, San Francisco, v.93, p.1217-1223, 2013.

CHACON, M.C.M. O relacionamento fraterno na presença da deficiência. Revista Espaço - Instituto Nacional de Educação de Surdos, Rio de Janeiro, n.33, p.70-82, 2010.

GOLDSMID, R.; FÉRES-CARNEIRO, T. Relação fraterna: constituição do sujeito e formação do laço social. Psicologia USP, São Paulo, v.22, n.4, p.771-788, 2011.

GRAFF, C. et al. Perspective of adolescent siblings of children with Down Syndrome who have multiple health problems. Journal of Family Nursing, Thousand Oaks, v.18, n.2, p.175-199, 2012.

HADJIKAKOU, K.; NIKOLARAIZI, M. The Communication Experiences of Adult Deaf People within their Family during Childhood in Cyprus. Deafness and Education International, New York, v.10, n.2, p.60-79, 2008.

MATSUKURA,bT.S.; CID, M.F.B. Irmãos de crianças com necessidades especiais: Buscando conhecer a realidade do outro. Revista Brasileira de Educação Especial, Marília, v.10, n.3, p.355-370, 2004.

MATSUKURA, T.S.; CID, M.F.B. Irmãos de crianças com necessidades especiais e suas famílias: diferentes expressóes sobre essa realidade. Cadernos de Terapia Ocupacional da UFSCar, São Carlos, v.16, n.1, p.7-16, 2008.

MATSUKURA, T.S.; YAMASHIRO, J.A. Relacionamento intergeracional, práticas de apoio e cotidiano de famílias de crianças com necessidades especiais. Revista Brasileira de Educação Especial, Marília, v.4, n.18, p.647-660, 2012.

MESSA, A.A.; FIAMENGHI JÚNIOR, G.A. O impacto da deficiência nos irmãos: histórias de vida. Ciênc. Saúde Coletiva, Rio de Janeiro, v.15, n.2, p.529-538, 2010.

MOURA, M.C. Surdez e Linguagem. In: LACERDA, C.B.F.; SANTOS, L.F. (Org.). Tenho um aluno surdo e agora? Sáo Carlos: Edufscar. 2013. p.13-26.

NAVARAUSCKAS, H. et al . “Ei, eu também estou aqui!”: aspectos psicológicos da percepção de irmãos frente à presença de uma criança com paralisia cerebral no núcleo familiar. Estud. psicol., Campinas, v.27, n.4, p.505-513, 2010.

NEGRELLI, M.E.D.; MARCON, S.S. Família e criança surda. Ciência, Cuidado e Saúde, Maringá, v.5, n.1, p.98-107, 2006.

NUNES, C.C.; DA SILVA, N.C.B.; AIELLO, A.L.R. As contribuiçôes do papel do pai e do irmão do indivíduo com necessidades especiais na visão sistêmica da família. Psicologia: Teoria e Pesquisa, Brasília, DF, v.24, n.1, p.37-44, 2008. 
OLIVEIRA, R.G. et al. A experiência de famílias no convívio com a criança surda. Acta Scientiarum. Health Sciences, Maringá, v.26, n.1, p.183-191, 2004.

PETEAN, E.B.L.; SUGUIHURA, A.L.M. Ter um irmão especial: convivendo com a síndrome de down. Revista Brasileira de Educação Especial, Marília, v.11, n.3, p.445-460, 2005.

SOARES, M.P.G.; FRANCO, A.L.S.; CARVALHO, A.M.A. Crianças que cuidam de irmãos com necessidades especiais. Psicologia: teoria e pesquisa, Brasília, DF, v.25, n.1, p.45-54, 2009.

SPINK, M.J. Práticas discursivas e produção de sentidos no cotidiano: aproximaçóes teóricas e metodológicas. 2. ed. São Paulo: Cortez, 2000.

REZENDE, I.G.; KROM, M.; YAMADA, M.O.A Repetição intergeracional e o significado atual da deficiência auditiva. Psicologia: Teoria e Pesquisa, Brasília, DF, v.19, n.2, p.177-184, 2003.

VICTORIA, C.G.; KNAUTH, D.R.; HASSUN, M.N.A. Pesquisa qualitativa em saúde: uma introdução ao tema. Porto Alegre: Tomo Editorial, 2000.

TAYLOR, J.L. et al. Siblings of adults with mild intellectual deficits or mental illness: differential life course outcomes. Journal of Family Psychology, Washington, v.22, n.6, p.905-914, 2008.

TURNBULL, A.P.; TURNBULL, H.R. Families, professionals and exceptionality: Collaboration for empowerment. 4. ed. Columbus: Merrill Publishing Company, 2001.

WOLFE, B. et al. Ripple effects of developmental disabilities and mental illness on nondisable adult siblings. Social Science and Medicine, New York, v.108, p.1-9, 2014.

YAMASHIRO, J.A.; MATSUKURA, T.S. Irmãos mais velhos de crianças com deficiência e de crianças com desenvolvimento típico: cotidiano e relacionamentos fraternos. Rev. Ter. Ocup. Univ. Sáo Paulo, São Paulo, v.24, n.2, p.87-94, 2013.

Recebido em: 16/07/2015

Reformulado em: 16/05/2016

Aprovado em: 30/05/2016 